\title{
Comparison of Meat Quality Traits, Free Amino Acid and Fatty Acid on Longissimus Lumborum Muscles from Hanwoo, Holstein and Angus Steers, Fattened in Korea
}

\author{
Dawoon Jeong ${ }^{1}$, Mi-Ra Oh, Pil-Nam Seong, Soohyun Cho, Geun-Ho Kang, Jin-Hyung Kim, \\ Seok-Geun Jeong, Jun-Soo Lee ${ }^{2}$, and Beom-Young Park* \\ Animal Products Research and Development Division, National Institute of Animal Science, RDA, \\ Suwon 441-706, Korea \\ ${ }^{1}$ Department of Animal Science, Chonbuk National University, Jeonju 561-756, Korea \\ ${ }^{2}$ Department of Food Science and Technology, Chungbuk National University, Cheongju 361-763, Korea
}

\begin{abstract}
This study was conducted to compare meat quality traits related to the tenderness of longissimus muscles obtained from domestic and imported steers. A total of 12 steers from three breeds were slaughtered, and were graded as quality grade 2. They were composed of 4 Hanwoo and 4 Holstein steers (domestic) as well as 4 Angus steers (imported from Australia and gained for six months in Korea until slaughtered). The longissimus lumborum muscles were separated and were stored at $4^{\circ} \mathrm{C}$ for 7 and $14 \mathrm{~d}$. Sarcomere length of Hanwoo was significantly shorter than Holstein and Angus at storage day 14 $(p<0.05)$. The myofibrillar index was significantly lower on Hanwoo than Angus at ageing day 7, and was significantly lower than Holstein and Angus steers at storage day $14(p<0.05)$. Total collagen contents of Hanwoo and Angus steers were significantly higher than Holstein on storage day $7(p<0.05)$, whereas soluble collagen contents of Holstein were significantly higher than Hanwoo and Angus on storage days 7 and $14(p<0.05)$. There was no significant difference in the fatty acid composition of the three breeds $(p>0.05)$. Glutamic acid contents of Hanwoo and Angus steers were higher than those of Holstein steers at ageing day 7 and $14(p<0.05)$. The results of this study have shown that there were no dramatic differences between beef from the three breeds that were fattened for 6 months under equal conditions.
\end{abstract}

Key words: Hanwoo, Holstein, Angus, tenderness, meat quality

\section{Introduction}

In South Korea, per capita consumption of meat has increased from $19.9 \mathrm{~kg}$ (1980) to $36.8 \mathrm{~kg}(2009)$ with lifting gross income, per capita consumption of beef also had been greatly increased till 2000, if per capita consumption in now. Amount of beef consumption in South Korea has jumped by ten times from $37300 \mathrm{M} / \mathrm{T}$ to $395500 \mathrm{M} / \mathrm{T}$ since 1970 . On the other hand, self-sufficiency ratio of beef was fell from 100 per cent to 36.6 per cent since 1970 (MIFAFF, 2010.8). However, recently it showed slightly increasing self-sufficiency ratio of beef, due to Bovine Spongiform Encephalopathy (BSE) outbreak in US, beef traceability in South Korea and enforc-

*Corresponding author: Beom-Young Park, Animal Products Research and Development Division, National Institute of Animal Science, RDA, Suwon 441-706, Korea. Tel: 82-31-290-1681, Fax: 82-31-290-1697, E-mail: byp5252@korea.kr ing indicate system of origin, but it was still less than other meats such as chicken and pork. Since 2001, South Korea opened customs for live beef cattle from overseas, total 6,860 heads of live beef cattle imported, 6,098 heads from Australia and 762 heads from United State, until May 2005. Then, the Rural Development Administration (RDA) declared a regulation that a meat from a cattle fed in Korea for above 6 months or over 6 months before slaughtered were indicated "Imported (Origin country)"or "Domestic (Origin country)"respectively for supervision to beef origin indication from importing live beef cattle (RDA regulation, 2001.9).

Several studies confirmed differences of meat quality between Hanwoo and imported beef; comparison of fatty acid composition between Hanwoo, Holstein and imported meat (Park and Yoo, 1994), comparison meat colour and physico-chemical traits (Kang et al., 1997; Kang et al., 1999; Kim et al., 1999; Lee et al, 2009a). Furthermore, only one case was reported by Park et al. 
(2002) that comparison meat physico-chemical properties of sirloin from Hereford, Angus, Murray Grey and Cross breed (Hereford $\times$ Angus). Meat tenderness was a major fact to percept taste of meat on consumers in South Korea (Cho et al., 2010) and also to be importantly considered when they purchased meat (Kim et al., 2009). The process of meat ageing was known that tough meat with rigor mortis became tender meat due to proteolysis in a meat conversed from muscle. In the same time, flavour was improved with tenderization (Lawrie, 1985). Park and Yoo (1994) studied to compare the palatability between Hanwoo, Cross breed and Holstein meat. According to their result, cross breed beef was tougher than Hanwoo and Holstein meat. Thus, this study was conducted to show objective information about meat tenderness, free amino acid contents and fatty acid contents of beef from Hanwoo, Holstein and Angus steers labelled the domestic on market condition.

\section{Materials and Methods}

\section{Animals and experiment design}

For this experiment, this research was designed to compare the meat tenderness between different three breeds (Hanwoo, Holstein and Angus) that consumers can closely and commonly eating in Korea. Both of Hanwoo and Holstein steers were born and grown in Korea (domestic), and Angus was born and grown in Australia until imported and/also gained for about 6 mon until slaughtered. Total 12 heads (4 heads per each breed) were slaughtered at a abattoir sited in Ochang-si and chilled for about $24 \mathrm{~h}$, after then carcasses were graded by Korean carcass-grading system (NLCF, 2004). A meat quality grade of all carcasses was given 2 grade, and longissimus lumborum muscle was detached from carcass and moved to laboratory at NIAS (National Institute of Animal Science, RDA) for analysis, the muscle samples were stored at $4{ }^{\circ} \mathrm{C}$ for $7 \mathrm{~d}$ and $14 \mathrm{~d}$.

\section{Warner-Bratzler shear force}

For mechanical determination of meat tenderness, the sample (thickness, $2.5 \mathrm{~cm}$ ) were put in a plastic bag, and heated in a $70^{\circ} \mathrm{C}$ water bath until the temperature of middle part in the sample was reached at $70^{\circ} \mathrm{C}$, and cooled for $30 \mathrm{~min}$ in flowing water at approximately $20^{\circ} \mathrm{C}$. WarnerBratzler shear force (WBsf) measurements were $1.27 \mathrm{~cm}$ circular core to determine sheared by cooked steaks $(2.5$ $\mathrm{cm}$ thick, cooked for determination of cooking loss) at 2 and $8 \mathrm{~d}$ of ageing. Eight cores were made for each sam- ple, and peak force determined using an Instron (4465, Instron corp., UK) with a load cell $50 \mathrm{~kg}$ and head speed $200 \mathrm{~mm} / \mathrm{min}$.

\section{Sarcomere length}

Sarcomere length was measured on a thin block $(1 \mathrm{~mm})$ of frozen muscle sample, which was in the direction of the muscle fibres. The thin block was homogenized for $30 \mathrm{sec}$ at low speed with glutaraldehyde, then fixed muscle fibres was drop on a microscope slide and covered using cover glass. Sarcomere length was measured using a Helium-Neon leaser (Lazerex Technologies PTY LTD., Australia) diffraction technique (Cross et al., 1980).

\section{Myofibrilar Fragmentation Index}

MFI was determined with $0.1 \mathrm{M}$ potassium chloride, 1 mM EDTA, $1 \mathrm{mM}$ sodium azid, $25 \mathrm{mM}$ potassium phosphate buffer ( $\mathrm{pH} 7.0$ ) followed the method of Hopkins (2000) modified Culler (1978). Myofibrilar fragment suspension was concentrated using DC protein assay kit (BIO-RAD, USA) with Bovine Serum Albumin used for the standard curve. The suspension was diluted to $0.5 \pm$ $0.05 \mathrm{mg} / \mathrm{mL}$ concentrations with potassium phosphate buffer, and then their absorbance was measured at 540 $\mathrm{nm}$ with a spectrophotometer (DU-800, Beckman, USA). It was multiplied the average of the triplicate absorbance by 150 , and the result was considered Myofibrilar fragmentation index values.

\section{Total Collagen and Heat Soluble Collagen contents}

Total collagen was measured using colorimetric determination of followed Kurt (1990). Sample was hydrolysis with $7 \mathrm{~N}$ sulphuric acid, oxidation with Chloramine-T, and colour formation with 4-dimethylaminobenzaldehyde. It was read at $558 \mathrm{~nm}$ with a spectrophotometer (DU-800, Beckman Coulter, USA), and total collagen contents were calculated using hydroxyproline concentration (eight times of hydroxyproline contents). Heat soluble collagen contents was determined, followed a method of Silva (1999). Sample was homogenized with $0.1 \mathrm{M}$ sodium phosphate buffer (pH 7.0), centrifuged at 10,000 rpm for $15 \mathrm{~min}$, and then supernatant was collected and determined using the same colorimetric method with total collagen contents. Also soluble collagen was calculated with 7.5 times absorbance.

\section{Fatty acid composition}

Fatty acid was extracted and evaporated following Folch's (1957) method, and methylated with a method of Morri- 
son and Smith (1964). Sample was analysed using gas chromatography (Varian 3600, Varian, USA). $1 \mu \mathrm{L}$ methylated sample was injected to Silica capillary column (Supelco-omegawax 320, $30 \mathrm{~m}, 0.32 \mathrm{~mm} \mathrm{ID,} 0.25 \mu \mathrm{m}$ ) and set $254^{\circ} \mathrm{C}$ injection temperature, $250^{\circ} \mathrm{C}$ detector temperature and $200^{\circ} \mathrm{C}$ oven temperature, and carry gas was $\mathrm{N}_{2}$.

\section{Free Amino Acid}

According to a method of Aristoy and Toldra (1991), free amino acid was extracted with $0.01 \mathrm{~N} \mathrm{HCl} .300 \mu \mathrm{L}$ extracted sample was mixed with $10 \mu \mathrm{L}$ internal standard (L-Citrulline) and $690 \mu \mathrm{L}$ Acetonitril, and mixed sample was incubated for $30 \mathrm{~min}$ at $4^{\circ} \mathrm{C}$, after then, centrifuged at $10,000 \times \mathrm{g}$ for $15 \mathrm{~min}$ kept at $4^{\circ} \mathrm{C}$. The supernatant was filtered through $0.45 \mu \mathrm{L}$ membrane filter. Filtered sample and external standard (amino acid standard: $0.25 \mathrm{nM}$, Agilent Technologies, USA; glutamine, Sigma) was analysed with OPA (O-phthalaldehyde) and FMOC (9-fluorenylmethyl chloroformate) derivatization using HPLC (Agilent, USA) of Herbert et al. (2000). Analysis condition was following a method (DAD detector, 262nm, 338 $\mathrm{nm}$; Column, Zorbax Eclipse AAA, 4.6×60 mm, $5 \mu \mathrm{m}$; column temp, $40^{\circ} \mathrm{C}$; Mobile phase $\mathrm{A}, 40 \mathrm{mM}$ sodium phosphate buffer, $\mathrm{pH} 7.8$; Mobile phase B, Acetonitril: Methanol:Water, 45:45:10, v:v:v) of Henderson et al. (2000).

\section{Sensory test}

The muscle samples were trimmed to a block $(40 \times 50$ $\mathrm{mm}$ ) with parallel to the muscle fibre. Then the block was sliced into $5 \mathrm{~mm}$ thickness to be rectangular with the muscle fibre, and then arranged randomly. Sensory properties were evaluated for tenderness (Extremely tough $=1$, Extremely tender $=8$ ), juiciness (Extremely dry $=1$, Extremely juicy $=8$ ), flavour intensity (Extremely bland=1, Extremely intense $=8$ ) and overall acceptability (Extremely bad $=1$, Extremely good=8) using eight-point descriptive scales by eight panels trained professionally.

\section{Statistical analysis}

Variance analysis and signification verify of this experiment was analyzed by using PROC GLM of SAS (2000) system.

\section{Results and Discussion}

Table 1 showed a result Warner-Bratzler shear force (WBsf), sarcomere length, and MFI of meat from Hanwoo, Holstein and Angus. WBsf of Hanwoo, Holstein and
Table 1. Warner-Bratlzer shear force, sarcomere length and Myofibril Fragmentation Index of M. longissimus lumborum from Hanwoo*, Holstein*, and Angus** steers stored at $4^{\circ} \mathrm{C}$ for 7 and $14 \mathrm{~d}$

\begin{tabular}{cccccc}
\hline \hline Items & $\begin{array}{c}\text { Storage } \\
\text { days }\end{array}$ & Hanwoo & Holstein & Angus & SEM*** \\
\hline Shear force & 7 & 4.53 & 4.39 & 3.62 & 0.42 \\
$\left(\mathrm{~kg} / 0.5\right.$ inch $\left.^{2}\right)$ & 14 & 3.74 & 3.53 & 3.19 & 0.39 \\
\hline Sarcomere & 7 & 1.83 & 1.91 & 1.94 & 0.05 \\
length $(\mu \mathrm{m})$ & 14 & $1.81^{\mathrm{b}}$ & $1.93^{\mathrm{a}}$ & $1.98^{\mathrm{a}}$ & 0.02 \\
\hline Myofibrillar & 7 & $89.21^{\mathrm{b}}$ & $93.39^{\mathrm{ab}}$ & $101.91^{\mathrm{a}}$ & 2.69 \\
index & 14 & $109.43^{\mathrm{b}}$ & $117.37^{\mathrm{a}}$ & $116.73^{\mathrm{a}}$ & 1.74 \\
\hline
\end{tabular}

$\overline{\mathrm{a}, \mathrm{b}}$ Means having different letters in the same row were significantly different $(p<0.05)$.

*Hanwoo and *Holstein, Born and raised in Korea

**Angus, Imported from Australia and gained for 6 mon in Korea ***SEM, Standard error means

Angus meats stored for day 7 were no significantly different on both of storage day 7 and $14(p>0.05)$, however WBsf of Hanwoo meat was shown to tend to lower WBsf with storage duration. Also WBsf of Hanwoo and Holstein meat were stored for $14 \mathrm{~d}$ was determined under 4.0 $\mathrm{kg}$ that can make consumers a pleasing meat tenderness. We expected that the higher WBsf on Hanwoo meat than others due to various age of each breed from different growing characters with different age when they was slaughtered. Universally, Hanwoo steers are killed age over 27 mon as slow growing breeds, however Holstein and Angus steers, which are fast growing breeds, are slaughtered at about 18-20 mon age.

Sarcomere length of Hanwoo beef at $7 \mathrm{~d}$ storage was shorter than Holstein and Angus, and there was no significant difference. At storage day 14, sarcomere length of Hanwoo beef was significantly shorter than Holstein and Angus $(p<0.05)$. This result was contrast with study of Kim (1999) that Hanwoo meat was shown longer sarcomere length than imported Australian beef. Myofibrillar index (MFI) was increasing with ageing (Warriss, 2010). Similarly, in our study showed that higher MFI longer storage day on all of three breeds. When compare MFI of three breeds on same storage days, MFI of Hanwoo beef stored for $7 \mathrm{~d}$ was determined to be significantly lower than Angus $(p<0.05)$, although these meat was stored for $14 \mathrm{~d}$, MFI of Hanwoo meat was lower than Holstein and Angus significantly $(p<0.05)$. Culler et al. (1978) reported that MFI is a good indicator to distinguish meat tenderness on beef. In this result, Angus meat showed the highest MFI among three different breeds. Therefore, Angus was evaluated great tender meat than other two breeds, 
Hanwoo and Holstein, meats. In contrast, Hanwoo meat was indicated lower tenderness than Holstein and Angus according to comparison of WBsf, sarcomere and MFI.

According to the study of McClain et al. (1970), tenderization of a meat closely concerned intramuscular connective tissue was decreased during storage, and Etherington (1987) reported meat tenderization was progressed due to weakening intramuscular connective tissue whilst a meat had storage duration, also collagen is major connective tissue among intramuscular connective tissue related meat tenderness. Collagen contents in intramuscular tissue had traits that animals were getting the more age, gradually getting the more toughness, firmness and unfixable on a meat of the animal (Jacques, 2008), also Bosselmann et al. (1995) suggested that there was strict relevance between collagen contents and meat tenderness. As studies of many authors, WBsf and tenderness related sensory trait was shown differences between different breeds or sex (Boles and Swan, 2002; Lee et al., 2009b; Mandell et al., 1997), whereas Chambaz et al. (2003) announced no significantly different shear force between breeds, which were Simmental, Charolaise and Limousin.

Fig. 1 showed total collagen contents and soluble collagen contents in Hanwoo, Holstein and Angus beef at ageing day 7 and 14. Total collagen contents of Hanwoo and Angus at day 7 were significantly higher than Hol-

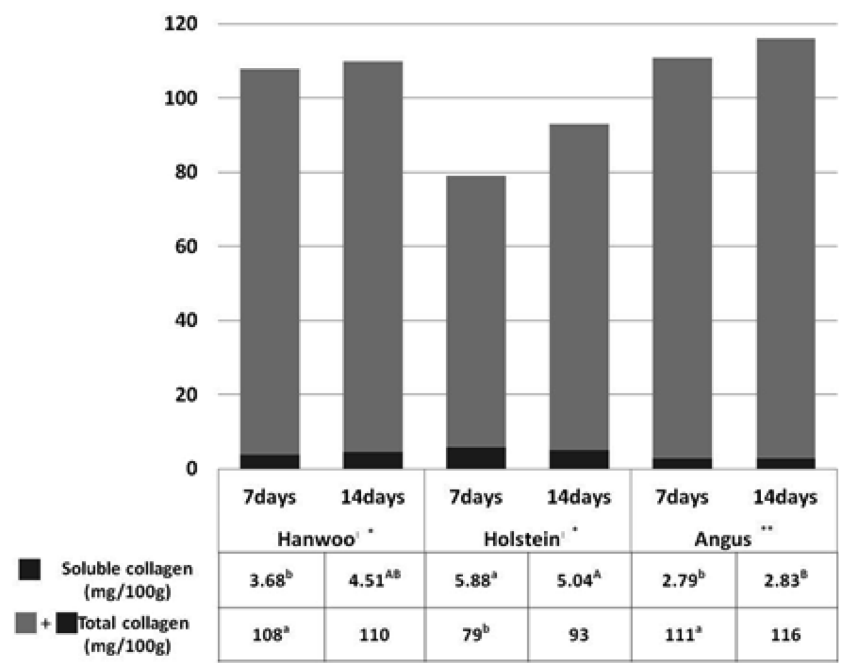

Fig. 1. Soluble and total collagen contents of M. longissimus lumborum from Hanwoo, Holstein and Angus steers stored at $4^{\circ} \mathrm{C}$ for 7 and $14 \mathrm{~d}$. SEM of total collagen, 0.06 ; SEM of soluble collagen 0.45 ; ${ }^{a, b}$ Means having different letters in the same row are significantly different on storage day $7(p<0.05)$. ${ }^{\mathrm{A}-\mathrm{B}}$ Means having different letters in the same row are significantly different on storage day $14(p<0.05)$. *Hanwoo and *Holstein, Born and raised in Korea. **Angus, Imported from Australia and then gained for about 6 mon in Korea). stein $(p<0.05)$, and at day 14, Holstein beef was obtained slightly lower total collagen percentage on the meat, however it was no significant difference of them. Recently, many researchers have been arguing whether negative relationship or else not between collagen contents and tenderness on meat (Moon et al., 2003; Purslow, 2005), Bosselmann et al. (1995) asserted that collagen contents in a meat has very close relevance with meat tenderness, whereas Lee et al (2009b) presented that instrumental tenderness on beef with different meat quality grades $(1++, 1$ and 2 ; Korean meat quality grading system) were measured clearly dissimilar, contrastively total collagen and soluble collagen contents of the meats were not any significant difference. Similarly our result was shown that WBsf and MFI related meat tenderness was not responded total collagen contents.

Soluble collagen contents in a meat at ageing day 7 of Holstein meat was significantly higher than Hanwoo and Angus $(p<0.05)$, also at ageing day 14 , Holstein meat soluble collagen contents was show significant different with Hanwoo and Angus $(p<0.05)$. The result of this experiment was demonstrated less relationship between collagen contents and tenderness contrasted with a result reported by Hill (1966) that is the more soluble collagen amount, the more tender on beef, otherwise our result was coincided with that Pierson and Fox (1976) proved soluble collagen contents did not affect tenderness of a meat because of that collagen solubility is not changed by ageing. Although Sañudo et al. (2004) reported a result of comparison meat quality by live weight, breeds and meat aging on beef, total collagen amount was not significant difference by live weight, nevertheless breeds was a acknowledged to influence total collagen contents by their study.

Fatty acid composition had an important role to develop meat quality on beef (Wood et al., 2008). Fatty acid composition of LL muscle from Hanwoo, Holstein and Angus was shown in the Table 2. SFA (Saturated Fatty Acid), myristic acid, palmatic acid and stearic acid, SFA of Angus was tended to higher than Hanwoo and Holstein at storage day 7. As a report of Hwang et al. (2004), flavour score was decreased with steric acid contents on beef, steric acid of the three breeds was that Angus was slightly higher than Hanwoo and Holstein. However steric acid of LL muscle from Hanwoo and Holstein were similar between them. Palmitoleic acid, which was found in animal fat and compounded from oleic acid (De Smet et al., 2004), was no significant difference between Hanwoo, Holstein and Angus on each 
Table 2. Fatty acid composition of $M$. longissimus lumborum from Hanwoo*, Holstein*, and Angus** steers stored for day 7 at $4^{\circ} \mathrm{C}$

\begin{tabular}{lcccc}
\hline \hline Fatty acids (\%) & Hanwoo & Holstein & Angus & SEM $^{* * *}$ \\
\hline Myristic acid & $0.91^{\mathrm{b}}$ & $3.26^{\mathrm{a}}$ & $2.23^{\mathrm{ab}}$ & 0.37 \\
Palmitic acid & 26.76 & 27.35 & 29.12 & 0.76 \\
Palmitoleic acid & 4.58 & 4.87 & 4.47 & 0.29 \\
Stearic acid & 11.67 & 11.73 & 12.24 & 0.60 \\
Oleic acid & 52.86 & 48.98 & 49.11 & 0.92 \\
Vaccenic acid & $0.21^{\mathrm{b}}$ & $0.06^{\mathrm{c}}$ & $0.27^{\mathrm{a}}$ & 0.01 \\
Linoleic acid & $1.86^{\mathrm{b}}$ & $2.77^{\mathrm{a}}$ & $1.60^{\mathrm{b}}$ & 0.10 \\
-Linoleic acid & 0.09 & 0.00 & 0.11 & 0.17 \\
Linolenic acid & $0.15^{\mathrm{b}}$ & $0.20^{\mathrm{a}}$ & $0.14^{\mathrm{b}}$ & 0.01 \\
Eicosenoic acid & $0.47^{\mathrm{a}}$ & $0.13^{\mathrm{b}}$ & $0.41^{\mathrm{a}}$ & 0.02 \\
Eicosadienoic acid & $0.08^{\mathrm{b}}$ & $0.31^{\mathrm{a}}$ & $0.05^{\mathrm{b}}$ & 0.01 \\
Eicosatrienoic acid & 0.12 & 0.14 & 0.10 & 0.01 \\
Arachidonic acid & 0.26 & 0.29 & 0.19 & 0.03 \\
\hline SFA & 39.34 & 42.34 & 43.60 & 1.00 \\
USFA & 60.67 & 57.67 & 56.41 & 1.00 \\
MUFA/SFA & 1.49 & 1.28 & 1.25 & 0.06 \\
PUFA/SFA & $0.07^{\mathrm{b}}$ & $0.09^{\mathrm{a}}$ & $0.05^{\mathrm{c}}$ & 0.00 \\
\hline
\end{tabular}

${ }^{\mathrm{a}-\mathrm{c}}$ Means having different letters in the same row are significantly different $(p<0.05)$.

*Hanwoo and *Holstein, Born and raised in Korea

**Angus, Imported from Australia and raised for 6 months in Korea. day 7 and 14. Oleic acid what is contained large amount of bovine adipose tissue, oleic acid contents in beef were various depended on breeds because of stearyl coenzyme A de-saturated gene activity related accumulation of oleic acid (De Smet et al., 2004). However in our study, oleic acid of Hanwoo beef was slightly higher than Holstein and Angus, but there was no significant difference. De Smet et al. (2004) studied that poly- and mono- saturated fatty acid ration was significantly different between grass feeding and grain feeding, especially oleic acid was greatly differed. On the contrast, in this study, there was not different on each saturated fatty acid contents between three breeds. Smith et al. (2009) presented that fatty acid composition of beef adipose tissue was depended by feeding, sex, breed, and age. The reason why the result showed no significant difference on fatty acid composition between the three breeds, the beef samples were collected from commercial market base. Previously numerous studies investigated differences of fatty acid composition between Hanwoo and imported beef (Cho et al., 2011; Hwang et al., 2004; Park and Yoo, 1994). However, as our result,

Table 3. Free amino acid contents of M. longissimus lumborum from Hanwoo*, Holstein*, and Angus** steers stored for 7 d and $14 \mathrm{~d}$ at $4^{\circ} \mathrm{C}$

\begin{tabular}{|c|c|c|c|c|c|c|c|c|}
\hline \multirow{2}{*}{ Free amino acids $(\%)$} & \multicolumn{4}{|c|}{ Day 7} & \multicolumn{4}{|c|}{ Day 14} \\
\hline & Hanwoo & Holstein & Angus & $\mathrm{SEM}^{* * *}$ & Hanwoo & Holstein & Angus & $\mathrm{SEM}^{* * *}$ \\
\hline Aspartic acid & Traces & Traces & Traces & - & Traces & Traces & Traces & - \\
\hline Glutamic acid & $3.08^{\mathrm{a}}$ & $1.26^{\mathrm{b}}$ & $3.63^{\mathrm{a}}$ & 0.33 & $4.04^{\mathrm{a}}$ & $1.83^{\mathrm{b}}$ & $4.24^{\mathrm{a}}$ & 0.31 \\
\hline Serine & $1.54^{\mathrm{ab}}$ & $1.23^{\mathrm{b}}$ & $1.84^{\mathrm{a}}$ & 0.13 & $2.01^{\mathrm{b}}$ & $1.84^{\mathrm{b}}$ & $2.80^{\mathrm{a}}$ & 0.13 \\
\hline Glutamine & $14.67^{\mathrm{b}}$ & $32.91^{\mathrm{a}}$ & $10.58^{b}$ & 1.72 & $12.13^{b}$ & $30.56^{\mathrm{a}}$ & $9.29^{b}$ & 0.32 \\
\hline Histidine & $3.49^{\mathrm{a}}$ & $1.76^{\mathrm{b}}$ & $2.92^{\mathrm{a}}$ & 0.21 & 3.16 & 2.39 & 2.80 & 0.19 \\
\hline Glycine & $2.16^{\mathrm{b}}$ & $1.72^{\mathrm{c}}$ & $2.77^{\mathrm{a}}$ & 0.12 & $2.21^{\mathrm{b}}$ & $2.01^{b}$ & $2.77^{\mathrm{a}}$ & 0.09 \\
\hline Threonine & $2.12^{\mathrm{a}}$ & $1.23^{\mathrm{b}}$ & $2.25^{\mathrm{a}}$ & 0.06 & $2.32^{\mathrm{b}}$ & $1.89^{c}$ & $2.67^{\mathrm{a}}$ & 0.04 \\
\hline Arginine & $5.36^{\mathrm{ab}}$ & $3.35^{\mathrm{b}}$ & $6.46^{\mathrm{a}}$ & 0.61 & $5.98^{\mathrm{a}}$ & $4.06^{\mathrm{b}}$ & $6.10^{\mathrm{a}}$ & 0.36 \\
\hline Alanine & 45.88 & 46.38 & 48.90 & 2.29 & 42.69 & 40.89 & 40.51 & 1.32 \\
\hline Tyrosine & $2.54^{\mathrm{a}}$ & $0.84^{\mathrm{c}}$ & $1.68^{\mathrm{b}}$ & 0.19 & $1.92^{\mathrm{b}}$ & $1.63^{b}$ & $2.88^{\mathrm{a}}$ & 0.17 \\
\hline Cystine & 3.18 & 0.77 & 2.71 & 0.15 & $2.35^{\mathrm{b}}$ & $0.87^{\mathrm{c}}$ & $3.32^{\mathrm{a}}$ & 0.12 \\
\hline Valine & $1.88^{\mathrm{a}}$ & $1.10^{\mathrm{b}}$ & $2.23^{\mathrm{a}}$ & 0.15 & $2.60^{\mathrm{b}}$ & $1.81^{\mathrm{c}}$ & $3.59^{\mathrm{a}}$ & 0.13 \\
\hline Methionine & $6.54^{\mathrm{a}}$ & $2.36^{\mathrm{b}}$ & $3.89^{\mathrm{ab}}$ & 0.81 & $6.16^{\mathrm{a}}$ & $1.19^{b}$ & $4.56^{\mathrm{a}}$ & 0.51 \\
\hline Phenylalanine & $1.84^{\mathrm{a}}$ & $0.96^{\mathrm{b}}$ & $1.59^{\mathrm{a}}$ & 0.15 & $2.22^{b}$ & $1.80^{\mathrm{b}}$ & $2.85^{\mathrm{a}}$ & 0.20 \\
\hline Isoleucine & 1.28 & 0.89 & 1.30 & 0.11 & $1.44^{\mathrm{b}}$ & $1.42^{\mathrm{b}}$ & $2.18^{\mathrm{a}}$ & 0.11 \\
\hline Leucine & $2.00^{\mathrm{b}}$ & $1.61^{\mathrm{b}}$ & $3.03^{\mathrm{a}}$ & 0.24 & $3.03^{\mathrm{b}}$ & $2.77^{\mathrm{b}}$ & $4.38^{\mathrm{a}}$ & 0.34 \\
\hline Lysine & $3.08^{\mathrm{a}}$ & $1.47^{\mathrm{b}}$ & $3.62^{\mathrm{a}}$ & 0.18 & $3.82^{b}$ & $2.45^{\mathrm{c}}$ & $4.97^{\mathrm{a}}$ & 0.14 \\
\hline Proline & 1.15 & 0.76 & 1.99 & 0.30 & $1.95^{\mathrm{a}}$ & $0.63^{b}$ & $2.46^{\mathrm{a}}$ & 0.20 \\
\hline Umami $^{1)}$ & $3.08^{\mathrm{a}}$ & $1.26^{\mathrm{b}}$ & $3.63^{\mathrm{a}}$ & 0.24 & $4.04^{\mathrm{a}}$ & $1.83^{\mathrm{b}}$ & $4.24^{\mathrm{a}}$ & 0.31 \\
\hline Sweet $^{2)}$ & 51.69 & 50.55 & 55.75 & 2.22 & 49.22 & 46.64 & 48.74 & 1.07 \\
\hline Bitter $^{3)}$ & $20.64^{\mathrm{a}}$ & $12.03^{\mathrm{b}}$ & $21.40^{\mathrm{a}}$ & 1.22 & $24.57^{\mathrm{a}}$ & $15.41^{b}$ & $25.76^{\mathrm{a}}$ & 0.95 \\
\hline Others ${ }^{4)}$ & $24.60^{\mathrm{b}}$ & $36.17^{\mathrm{a}}$ & $19.21^{\mathrm{b}}$ & 2.23 & $22.17^{\mathrm{b}}$ & $36.12^{\mathrm{a}}$ & $21.26^{\mathrm{b}}$ & 1.52 \\
\hline
\end{tabular}

${ }^{a-c}$ Means having different letters in the same row are significantly different at the same stored days $(p<0.05)$.

*Hanwoo and *Holstein, Born and raised in Korea

**Angus, Imported from Australia and raised for 6 months in Korea

***SEM, Standard error mean

${ }^{1)}$ Umami, Aspartic acid and glutamic acid

${ }^{2}$ Sweet, Threonine, serine, glycine and alanine

${ }^{3)}$ Bitter, Valine, methionine, isoleucine, leucine, phenylalanine, histidine and arginine

${ }^{4)}$ Others, Glutamine, tyrosine, cysteine, lysine and proline 
when consumers purchase domestic beef, the domestic beef in the market had no differences of fatty acid composition.

Apart from nutritional aspect, free amino acid is very important non-volatile materials for meat taste and flavour (Gardner and Sterwart, 1966; Davey and Gilbert, 1966), free amino acids from heated meat improve meat flavour (Ockerman and Cresopo, 1982). Tseng et al. (2005) classified free amino acid in food to umami (aspartic acid, glutamic acid), sweet (serine, glycine, threonine, alanine), bitter (valine, methionine, isoleucine, leucine, phenylalanine, histidine, arginine), and others (Glutamine, tyrosine, systine, lysine and proline). In our study, glutamic acid, umami taste, of Hanwoo and Angus had significantly higher percentage than Holstein beef at storage day 7 and $14(p<0.05)$. Angus beef had significantly higher percentage of serine, glycine, and threonine those belong to sweet taste group than Holstein at day 7. Hanwoo and Angus beef contained more bitter taste free amino acids than Holstein significantly $(p<0.05)$ at day 7 and 14 . Free amino acid contents were increased with acid lipase and protease that released from lysosome during ageing (Geromel and Montgomery, 1980), meat taste and flavour were affected these variations (Koutsidis et al., 2007; Koutsidis et al., 2008; Tseng et al., 2005). Feidt et al. (1996) reported that glycine, threonine, alanine, methionine, isoleucine, and leucine were increased with ageing period on longissimus dorsi muscle, in this study, similarly glycine, threonine, and leucine percentage at day 14 on all of three breeds was higher than day 7 .

In general terms, the results of this study have showed that no distinctive differences found between Hanwoo, Holstein and Angus beef that were fattened for 6 months in market base. However this study was conducted on real market base in Korea, thus it can be consumed to reflect a condition for consumer-meat market. Moreover, this study has provided basic information about meat quality and precursor of taste of the three breed fed in Korea.

\section{References}

1. Aristoy, M. C and Toldra, F. (1991) Deproteinization techniques for HPLC amino acid analysis in fresh pork muscle and dry-cured ham. J. Agri. Food Chem. 39, 1792-1795.

2. Boles, J. A. and Swan, J. E. (2002). Processing and sensory characteristics of cooked roast beef : effect of breed, age, gender and storage conditions. Meat Sci. 62, 419-427.

3. Bosselmann, A., Moller, C., Steinhart, H., Kirchgessner, M., and Schwartz, F. J. (1995) Pyridinoline cross-links in bovine muscle collagen. J. Food Sci. 60, 953-958.

4. Chambaz, A., Scheeder, M. R. L., Kreuzer, M., and Dufey, P. A. (2003) Meat quality of Angus, Simmental, Charolais and Limousin steers compared at the same intramuscular fat content. Meat Sci. 63, 491-500.

5. Cho, S. H., Kim, j., Park, B. Y., Seong, P. N., Jang, G. H., Kim, J. H., Jung, S. G., Im, S. K., and Kim, D. H. (2010) Assessment of meat quality properties and development of a palatability prediction model for Korean Hanwoo steer beef. Meat Sci. 86, 236-242.

6. Cho, S. H., Kang, G. H., Seong, P. N., Park, B. Y., Jung, S. K., Kang, S. M., Kim, Y. C., Kim, J. H., and Kim, D. H. (2011) Meat quality and nutritional properties of Hanwoo and imported New Zealand beef. Korean J. Food Sci. An. 31, 935943.

7. Cross, H. R., West, R. L., and Dutson, T. R. (1980) Comparison of methods for measuring sarcomere length in beef semitendinosus muscle. Meat Sci. 5, 261-266.

8. Culler, R. D., Parrish F. C. Jr., Smith G. C., and Cross H. R. (1978) Relationship of myofibril fragmentation index to certain chemical, physical and sensory characteristics of bovine longissimus muscle. J. Food Sci. 43, 1177-1180.

9. Davey, C. L. and Gilbert, K. V. (1966) Studies in meat tenderness. II. Proteolysis and the aging of beef. J. Food Sci. 31, 135-140.

10. De Smet, S., Raes, K., and Demeyer, D (2004) Meat fatty acid composition as affected by fatness and genetic factors: a review. Anim. Res. 53, 81-98.

11. Etherington, D. J. (1987) Collagen and meat quality; Effects of conditioning and growth rate In "Adv. In Meat Res."Vol. 4ed. By Pearson, A. M., AVI pub. Co. Westport, Conneticut, p. 351.

12. Feidt, C., Petit, A., Bruas-Reignier, F., and Brun-Bellut, J. (1996). Release of free amino-acids during ageing in bovine meat. Meat Sci. 44, 19-25.

13. Folch, J. M., Lee, M., and Sloan, Stanley G. H. (1957) A simple method for the isolation and purification of total lipids from animal tissues. J. Biol Chem. 226, 505.

14. Gardner, G. A and Sterwart, D. J. (1966) Changes in the free amino and other nitrogen compounds in stored beef muscle. J. Sci. Food Agric. 17, 419-496.

15. Geromel, E. J. and Montgomery, M. W. (1980). Lipase release from lysosomes of Rainbow Trout (salmo gairdneri) muscle subjected to low temperatures, J. Food Sci. 45, 412.

16. Henderson, J. W., Ricker, R. D., Bidlingmeyer, B. A. and Cliff, W. (2000). Rapid, accurate, sensitive, and reproducible HPLC analysis of amino acids. Agilent Technologies.

17. Herbert, P., Barros, N., Ratola and A. Alves. (2000) HPLC determination of amino acids in musts and port wine using OPA/FMOC derivatives. J. Food Sci., 65, 1130-1133.

18. Hill, F. (1966) The solubility of intramuscular collagen in meat animals of various ages. J. Food. Sci., 31, 161-166.

19. Hopkins. D. L., Littlefield, P. J., and Thompson J. M. (2000) A research note on factors affecting the determination of myofibrillar fragmentation. Meat Sci., 56, 19-22.

20. Hwang, I. H., Park, B. Y., Cho, S. H., Kim, J. H., and Lee, J. 
M. (2004) Meat quality of highly marbled imported beef with reference to Hanwoo. Kor. J. Anim. Sci \& Technol. 46, 1-8.

21. Jacques, L. (2008) Collagen contribution to meat tendernessTheoretical aspects. Meat Sci., 80, 960-967.

22. Kang, J. O., Lee, J. H., and Kim, C. J. (1997) Studies on the color, $\mathrm{pH}$ and bacterial count of Hanwoo (Korean cattle) beef imported beef. Korean J. Anim. Sci., 39, 275-280.

23. Kang, O. J., Choi, D. Y., Oh, H. R., and Kim, G. H. (1999) Comparison of physico-chemical characteristics of the meat quality grades in Hanwoo beef and imported beef from several countries-A consideration on meat color, fat color and maturity. Korean J. Anim. Sci., 41, 555-562.

24. Kim, G. J., Byun, G. I., and Jung, W. S. (2009) A study on the potential effects of consumer preference for beef and involvement in the attributes of beef selection on consumers purchase intentions. Korean J. Culinary Res. 15, 286-298.

25. Kim, I. S., Lee, S. O., Kang, S, N., Byun, J. S., and Lee, M. (1999) The physicochemical, microbial and sensory characteristics of Han-Woo and imported chilled beef loins. Korean J. Food Sci. Ani. Resour., 19, 331-338.

26. Koutsidis, G., Elmore, J. S., Oruna-Concha, M, J., Campo, M. M., Wood, J. D., and Mottram, D. S. (2007). Water soluble precursors of beef flavor. Part: Effect of diet and breed. Meat Sci. 79, 124-130.

27. Kurt, K. (1990) Colorimetric determination of hydroxyproline as measure of collagen contents in meat and meat products:NMKL Collaborative Study. J. Assac. Off. Anal. Chem. 73, p. 52.

28. Koutsidis, G., Elmore, J. S., Oruna-Concha, M. J., Campo, M. M., Woo, J. D., and Mottram, D. S. (2008) Water-soluble precursors of beef flavour. PartII: Effect of post mortem conditioning. Meat Sci. 79, 270-277.

29. Lawrie, R. A. (1985) Meat science. $4^{\text {th }}$ ed, In: Chemical and Biochemical Constitution of Muscle. Lawrie, R. A. (ed) Pergamon Press, NY, pp. 82.

30. Lee, J. M., Kim, T. W., Kim, J. H., Cho, S. H., Seong, P. N., Jung, M. O., Cho, Y. M., Park, B. Y., and Kim, D. H. (2009a) Comparison of chemical, physical and sensory traits of longissimus lumborum Hanwoo beef and Australian Wagyu beef. Korean J. Food Sci. Ani. Resour. 29, 91-98.

31. Lee, Y. J., Kim, C. J., Park, B. Y., Seong, P. N., Kim, J. H., Kang, G. H., Kim, D. H., and Cho, S. H. (2009b) WarnerBratzer shear force, sarcomere length, total collagen contents and sensory characteristics of Hanwoo beef (Korean native cattle) quality grade. Korean J. Food Sci. Ani. Resour. 29, 726-735.

32. Mandell, I. B., Gullett, E. A., Wilton, J. W., Kemp, R. A., and Allen, O. B. (1997) Effects of gender and breed on carcass traits, chemical composition, and palatability attributes in Hereford and Simmental bulls and steers. Livestock Prod. Sci. 49, 235-248.

33. McClain, P. E., Creed, G. J., Wiley, E. R., and Homstein, I. (1970) Effect of postmortem aging on isolation of intramuscular connective tissue. J. Food Sci. 35, 258-259.

34. MIFAFF (2010. 8) The statistical research of food, agricul- ture, forestry and fisheries 2010. MIFAFF Ministry for Food, Agriculture, Forestry and Fisheries, South Korea, Hanla publisher.

35. Moon, S. S., Kang, G. H., Hur, S. J., Jeong, J. Y., Yang, H. S., Kim, J. S., Joo, S. T., and Park, G. B. (2003) Effect of carcass traits, sarcomere length and meat quality properties on beef longissimus tenderness at $24 \mathrm{hr}$ postmortem. Kor. J. Food Sci. 23, 109-114.

36. Morrison, W. R. and Smith, L. M. (1964) Preparation of fatty acid methylesters and dimethylacetals from lipid with boron fluoridemethanol. J. Lipid Res. 5, 600-608.

37. NLCF (2004) Korean carcass grading system standard. National Livestock Cooperative Federation, Korea.

38. Ockerman, H. W. and Cresopo, F. L. (1982) Physicochemical changes occuring during storage of precured beef blends at different temperature and two levels of salt. J. Food Sci. 47, 849.

39. Park, B. S. and Yoo, I. J. (1994) Comparison of fatty acid composition among imported beef, Holstein steer beef and Hanwoo beef. Korean J. Anim. Sci. 36, 69-75.

40. Park, B. Y., Cho, S. H., Yoo, Y. M.m Lee, S. J., Chae, H. S., Kim, J. H., Hong, S. K., and Lee, J. M. (2002) Physicochemical properties for sirloin domestic fed imported beef cattle. Korean J. Food Sci. An. 22, 218-221.

41. Pierson, C. J. and Fox, J. D. (1976) Effect of postmortem aging time and temperature on $\mathrm{pH}$, tenderness and soluble collagen fraction in bovine longissimus muscle. J. Anim. Sci. 43, 12061210.

42. Purslow, P. P. (2005) Intramuscular connective tissue and its role in meat quality. Meat Sci. 70, 435-447.

43. RDA (2001. 9) The management of imported beef cattle. Rural Department Administration, South Korea, RDA Regulation 2001-2055.

44. Sañudo, C., Macie, E. S., Olleta, J. L., Villarroel, M., Panea, B., and Albertí, P. (2004) The effects of slaughter weight, breed type and ageing time on beef meat quality using two different texture devices. Meat Sci. 66, 925-932.

45. SAS (2000) SAS/STAT user's guide. 8th ed. SAS Institute Inc. Cary NC., USA.

46. Silva, J. A., Patarata, L., and Martins, C. (1999) Influence of ultimate $\mathrm{pH}$ on bovine meat tenderness during ageing. Meat Sci. 52, 453-459.

47. Smith, S. B., Gill, C. A., Lunt, D. K, and Brooks, M. A. (2009) Regulation of fat and fatty acid composition in beef cattle. Asian-Aust. J. Anim. Sci. 22, 1225-1233.

48. Tseng, Y. H., Lee, R. C., Li, J. L., and Mau, J. L. (2005) Nonvolatile flavour components of ganoderma tsugae. Food Chem. 90, 409-415.

49. Warriss. P. D. (2010) Meat Science : an introductory text/ Paul Warriss, $2^{\text {nd }}$ ed. CABI, p. 72.

50. Wood, J. D., Enser, M., Fisher, A. V., Nute, G, R., Sheard, P. R., Richardson, R. I., Hughes, S. I., and Whittington, F. M. (2008). Fat deposition, fatty acid composition and meat quality: A review. Meat Sci. 78, 343-358.

(Received 2011.9.15/Revised 2012.7.4/Accepted 2012.9.13) 